\title{
The application of prophylactic balloon occlusion of the internal iliac artery for the treatment of placenta accreta spectrum with placenta previa: a retrospective case- control study
}

\author{
Ying Peng*, Lai Jiang, Cheng Peng, Dabao Wu and Ling Chen
}

\begin{abstract}
Background: Severe obstetric haemorrhage caused by placenta accreta spectrum (PAS) results in significant maternal morbidity and mortality. The effectiveness of prophylactic balloon occlusion of the internal iliac artery in PAS patients remains controversial. Therefore, we conducted a retrospective case-control study to investigate the clinical effectiveness of this treatment.

Methods: The clinical data of 104 patients with PAS complicated with placenta previa who delivered by caesarean section between January 2016 and January 2019 were collected, and the patients were divided into two groups. The study group (48 cases) underwent internal iliac artery preset balloon occlusion before caesarean section and uterine artery embolisation according to the bleeding status after surgery, while the control group (56 cases) did not undergo internal iliac artery preset balloon occlusion before caesarean section.

Results: The operation and hospitalisation times in the study group were longer than those in the control group. Additionally, the hysterectomy rate in the study group was significantly higher than that in the control group. No significant differences in blood loss, blood transfusion volume, urinary system injury, postoperative ICU transfer rate, or neonatal scores were identified between the groups. Among the patients without invasive placenta (placenta increta and percreta), blood loss was lower in the study group, and the caesarean hysterectomy rate did not significantly differ between the groups. Among the patients with invasive placenta, blood loss and the caesarean hysterectomy rate did not significantly differ between the groups. The risk of hysterectomy in the study group was related to invasive placenta penetration, a large area of placental invasion, or abnormal vascular filling. One patient in the study group had a thrombus in the left lower extremity artery.
\end{abstract}

(Continued on next page)

\footnotetext{
*Correspondence: peng961390@126.com

Department of Obstetrics and Gynecology, First Affiliated Hospital of University of Science and Technology of China (Anhui Provincial

Hospital, China), Hefei 230001, Anhui Province, China
}

(c) The Author(s). 2020 Open Access This article is licensed under a Creative Commons Attribution 4.0 International License, which permits use, sharing, adaptation, distribution and reproduction in any medium or format, as long as you give appropriate credit to the original author(s) and the source, provide a link to the Creative Commons licence, and indicate if changes were made. The images or other third party material in this article are included in the article's Creative Commons licence, unless indicated otherwise in a credit line to the material. If material is not included in the article's Creative Commons licence and your intended use is not permitted by statutory regulation or exceeds the permitted use, you will need to obtain permission directly from the copyright holder. To view a copy of this licence, visit http://creativecommons.org/licenses/by/4.0/ The Creative Commons Public Domain Dedication waiver (http://creativecommons.org/publicdomain/zero/1.0/) applies to the data made available in this article, unless otherwise stated in a credit line to the data. 
(Continued from previous page)

Conclusions: Balloon occlusion of the internal iliac artery is effective for haemostasis of placenta previa in the absence of invasive placenta. For patients with invasive placenta, especially placenta percreta, a large area of placental invasion or abnormal vascular filling suggests the need for hysterectomy. The risks of the prophylactic use of internal iliac artery balloon occlusion include vascular injury and thrombus formation.

Keywords: Placenta accreta spectrum, Embolisation of the internal iliac artery, Caesarean section

\section{Background}

Placenta accreta spectrum (PAS) was first described by Chattopadhyay et al. [1] in 1993 as the main cause of obstetric haemorrhage and perinatal hysterectomy [2, 3]. PAS is classified into three subtypes depending on the depth of placental invasion: abnormally adherent placenta (placenta adherenta or accreta), abnormally invasive placenta (increta), and abnormally invasive placenta (percreta) [4, 5]. In recent years, due to increases in the caesarean section rate and uterine cavity operation rate, the incidence of PAS has increased, and the incidence of related postpartum haemorrhage has also increased [6]. Uncontrollable postpartum haemorrhage can occur when PAS is present in combination with placenta previa [7-9]. Caesarean section is the main treatment method for PAS, and haemorrhage control during the operation is key for successful treatment. When traditional methods such as uterine cavity compression [10,11], uterine cavity water sac compression [12,13], uterine compression suturing $[14,15]$, or uterine artery or internal iliac artery ligation $[16,17]$ cannot control massive haemorrhage, hysterectomy is required $[18,19]$. However, hysterectomy results in physiological damage to the patient and imposes a mental burden on parturients and their families. Preventive placement of balloons in the bilateral internal iliac arteries before caesarean section can reduce uterine artery pressure and intraoperative blood loss during balloon inflation, thus temporarily blocking the main blood supply of the uterus, helping to expose the visual field, shortening the operation time during surgery, and leading to opportunities for timely adjustments to the operative plan during surgery. However, no consensus is available on its safety and effectiveness. In this paper, the clinical data of 104 patients with PAS complicated with placenta previa who underwent caesarean section and were admitted to our hospital between January 2016 and January 2019 were collected to investigate the clinical effect of internal iliac artery embolisation in PAS.

\section{Methods}

Data

The clinical data of 104 patients with PAS who underwent caesarean section and were admitted to our department from January 2016 to January 2019 were collected. The typical B-ultrasound findings were based on the detection of at least two of the following characteristics: 1) loss/irregularity of the hypoechoic area between the uterus and placenta depicted as a 'retroplacentar clear zone'; 2) thinning/interruption of the uterine serosabladder wall interface; 3 ) myometrial thickness ( $<1 \mathrm{~mm})$; 4) turbulent placental lacunae with high-velocity flow (>15 cm/s); 5) the presence of increased vascularity of the uterine serosa-bladder wall interface; and 6) loss of the vascular arch parallel to the basal plate and irregular intraplacental vascularisation [20-23]. All patients underwent caesarean section.

\section{Inclusion criteria}

The inclusion criteria were: 1) availability of Bultrasound examination and/or pelvic MR plain scans; 2) singleton pregnancies; 3) gestational age $\geq 28$ weeks; 4) a history of caesarean section; and 5) a desire to continue giving birth. The exclusion criteria were: 1) serious internal or surgery-related disease; or 2) a tendency for bleeding. All patients were fully informed of the study and surgical procedure by their doctors and signed informed consent forms, and the research was approved by the Biomedical Research Ethics Committee of our hospital.

Area and weighing methods were used to measure bleeding volume. The area method was used to estimate the amount of blood loss according to the wet gauze blood area. For the weighing method, a pre-weighed towel was spread under the buttocks of the parturient. The wet weight of the dressing (g) was measured after bleeding, and the dry weight of the dressing (g)/1.05 (blood specific gravity $\mathrm{g} / \mathrm{ml}$ ) was measured before bleeding.

\section{Observation group \\ Study group}

Balloon occlusion of the bilateral internal iliac arteries was performed. The procedure began with routine disinfection, followed by towel spreading and the administration of local anaesthesia with $2 \%$ lidocaine. After successful puncture through the right and left femoral arteries using the Seldinger technique, 7F arterial catheter sheaths were placed on the left and right sides. A balloon catheter was inserted into the appropriate position of the main trunk of the common iliac artery on 
the same side by means of guide wire anchoring and catheter exchange techniques. A small amount of contrast agent was injected to confirm that the balloon catheter was located in the internal iliac artery, and the position of the balloon catheter and arterial sheath was fixed. Immediately after delivery, the balloon was filled to block blood flow. According to the amount of intraoperative haemorrhage and placental accretion of the parturient, pulse embolisation, promotion of uterine contraction, and other treatments were carried out. If no active bleeding was evident, the bilateral internal iliac artery balloon was removed after caesarean section.

\section{Control group}

Caesarean section was performed routinely. After delivery, uterine massage, surface suturing after placental stripping for haemostasis, administration of a uterine contraction agent, and gauze packing in the uterine cavity were performed meticulously according to the specific conditions of the patient during the operation. According to the specific condition of the patient, total hysterectomy or subtotal hysterectomy was performed when necessary.

\section{Statistical analysis}

EXCEL 2003 (Microsoft Corp., Redmond, WA) was used for data entry and sorting. SPSS 19.0 (IBM Corp., Armonk, NY) was used for data analysis. Age, the number of gestational weeks, the number of pregnancies, the number of caesarean sections, operation time, intraoperative bleeding volume, blood transfusion volume, postoperative hospitalisation length, new-born APGAR score, and other measurement data were compared by means of independent two-sample t-tests. A chi-square test was used to compare the invasive placenta rate, the hysterectomy rate, the placenta percreta rate, the rate of a placental invasive area $>1 / 2$, the rate of abnormal vascular filling, etc. The puerperal infection rate, urinary system injury rate, and intensive care unit (ICU) occupancy rate were compared using Fisher's exact test, with $P<0.05$ indicating a significant difference.

\section{Results}

The patients were divided into a study group and control group according to whether they received balloon occlusion of the internal iliac artery. The study group included 48 patients ranging in age from 22 to 41 years, with an average age of $32.08 \pm 3.94$ years. The number of gestational weeks ranged from $28+6$ to $39+4$ weeks, with an average of $35 \pm 2$ weeks. The patients had been pregnant 1 to 5 times, with an average of $2.81 \pm 1.30$ pregnancies. The average number of caesarean sections was $1.19 \pm 0.45$. There were 28 cases with invasive placenta in the study group. The control group comprised 56 patients aged 26 to 44 years, with an average age of $33.46 \pm 4.53$ years. The number of gestational weeks ranged from $30+4$ to $39+2$ weeks, with an average of $36 \pm 2$ weeks. The patients had been pregnant 1 to 7 times, with an average of $3.23 \pm 1.53$ pregnancies. The average number of caesarean sections was $1.18 \pm 0.39$, and there were 25 cases with invasive placenta. No significant differences in age, the number of gestational weeks, the number of pregnancies, the number of caesarean sections, or the number of invasive placenta events were identified between the two groups $(P>0.05)$, as shown in Table 1.

We compared the two groups in terms of the operation time, intraoperative bleeding volume, blood transfusion volume, postoperative hospitalisation length, hysterectomy rate, urinary system injury rate, puerperal infection rate, ICU admission rate, and new-born APGAR score. We found that the operation time, postoperative hospitalisation time, and hysterectomy rate were significantly higher in the study group than in the control group (operation time: $158.44 \pm 57.31 \mathrm{~min}$ vs. $104.2 \pm 46.22 \mathrm{~min}$; postoperative hospitalisation time: $7.02 \pm 3.77$ days vs. $5.70 \pm 2.57$ days; and hysterectomy rate: $29.2 \%$ vs. $12.5 \%, P<0.05)$. No significant differences were found between the two groups in terms of the intraoperative haemorrhage volume, blood transfusion volume, urinary system injury rate, puerperal infection rate, ICU admission rate, and 1-min or 5-min APGAR score, as shown in Table 2.

Among the patients without invasive placenta, the amount of bleeding in the study group was significantly lower than that in the control group. No hysterectomies were performed in the 18 patients who underwent balloon occlusion. Among the 31 patients who did not undergo balloon occlusion, the hysterectomy rate was $3.23 \%$. The difference was not statistically significant, as shown in Table 3.

Among the patients with an invasive placenta, the differences in the mean blood loss and hysterectomy rate between the two groups were not statistically significant as shown in Table 4.

We compared the patients in the study group who did and did not undergo hysterectomy in terms of invasive placenta penetration (as shown in Fig. 1), a placental invasive area $>1 / 2$ (as shown in Fig. 2), abnormal vascular filling (as shown in Figs. 3 and 4) and the number of caesarean sections. The rates of invasive placenta penetration, a placenta invasive area $>1 / 2$ and abnormal vascular filling in the hysterectomy group were significantly $(P<0.05)$ higher than those in the unresected group $(85.7,92.9$, and $85.7 \%$ vs. $11.8,26.5$, and $23.5 \%$, respectively) as shown in Table 5.

\section{Discussion}

The purpose of this study was to investigate the clinical effect of internal iliac artery balloon occlusion in patients 
Table 1 Comparison of general data between the control group and study group

\begin{tabular}{|c|c|c|c|c|}
\hline & Control group & Study group & $\mathrm{t}(\mathrm{X} 2)$ & $P$ \\
\hline N & 56 & 48 & & \\
\hline Age, years (mean $\pm S D$ ) & $33.46 \pm 4.53$ & $32.08 \pm 3.94$ & 1.65 & 0.103 \\
\hline Gestational weeks (mean \pm SD) & $36.05 \pm 1.66$ & $35.57 \pm 1.97$ & 1.36 & 0.177 \\
\hline Number of pregnancies (mean \pm SD) & $3.23 \pm 1.53$ & $2.81 \pm 1.30$ & 1.54 & 0.138 \\
\hline Number of caesarean sections (mean \pm SD) & $1.18 \pm 0.39$ & $1.19 \pm 0.45$ & -0.11 & 0.913 \\
\hline Invasive placenta [N (\%)] & $25(44.64 \%)$ & $28(58.33 \%)$ & 1.938 & 0.164 \\
\hline
\end{tabular}

SD Standard deviation.

with PAS and placenta previa. Postpartum haemorrhage is one of the main causes of maternal death [24, 25]. PAS often causes uncontrollable bleeding. Balloon occlusion of the internal iliac artery can temporarily block the internal iliac artery, effectively reduce the blood supply of the uterine artery and save the time available for the actual surgery. Although some studies have shown that preoperative prophylactic arterial catheterisation can reduce blood loss and transfusion demands in patients with placental invasion and help maintain fertility, its effectiveness in PAS remains controversial. Gulino et al. [26] reported 37 cases of placenta accreta, including 16 cases in a balloon group and 21 cases in a non-balloon group. Bleeding, the blood transfusion volume, and the rate of hysterectomy were lower in the balloon group than in the non-balloon group. Carnevale et al. [27] also concluded that preventive internal iliac artery balloon occlusion can reduce the amount of bleeding and blood transfusion in patients with placenta accrete after caesarean section and that this method is safe. However, preventive internal iliac artery balloon occlusion is not effective in all cases [28-32].

In this study, balloon placement did not reduce the amount of intraoperative bleeding or the rate of hysterectomy. The operation time and postoperative hospital stay were longer in the study group than in the control group. Further grouping showed that the bleeding volume of patients without an invasive placenta decreased after the balloon placement, supporting the haemostasis effect of internal iliac artery balloon occlusion for non-invasive placenta, whereas the bleeding volume effect in the patients with an invasive placenta was not obvious.

Shrivastava et al. [31] believe that the failure of internal iliac artery balloon occlusion to reduce blood loss may be due to excessive uterine blood flow during pregnancy and extensive intrapelvic vascular anastomosis. In addition to uterine artery support, the blood supply of the uterus also includes the obturator artery, ovarian artery and femoral artery [33, 34]. In PAS with placenta previa, the placenta is mostly located in the lower part of the uterus, the cervix and the upper part of the vagina, where many abnormal vascular anastomotic branches exist $[35,36]$. Through the extensive collateral circulation between the arteries in the pelvis, the branches originating from other blood vessels (i.e., the external iliac artery or the femoral artery) can quickly compensate for the occluded arteries of the uterus, which is not

Table 2 Comparison of maternal surgery and neonatal scores between the control group and the study group

\begin{tabular}{|c|c|c|c|c|}
\hline & Control group & Study group & $\mathrm{t}(\mathrm{X} 2)$ & P \\
\hline N & 56 & 48 & & \\
\hline Operation time, min (mean \pm SD) & $104.20 \pm 46.22$ & $158.44 \pm 57.31$ & -5.34 & 0 \\
\hline Intraoperative bleeding volume, $\mathrm{ml}$ (mean \pm SD) & $1108.04 \pm 1008.32$ & $1504.17 \pm 1123.44$ & -1.9 & 0.061 \\
\hline Blood transfusion volume, $\mathrm{ml}$ (mean $\pm \mathrm{SD}$ ) & $970.54 \pm 1083.21$ & $1352.08 \pm 1211.03$ & -1.70 & 0.093 \\
\hline Postoperative hospitalisation length, days (mean \pm SD) & $5.70 \pm 2.57$ & $7.02 \pm 3.77$ & -2.06 & 0.043 \\
\hline Hysterectomy [N (\%)] & $7(12.5 \%)$ & $14(29.2 \%)$ & 4.45 & 0.035 \\
\hline Urinary system injury & $3(5.36 \%)$ & $4(8.33 \%)$ & & $0.701^{*}$ \\
\hline Puerperal infection [N (\%)] & $0(0.0 \%)$ & $2(4.2 \%)$ & & $0.211^{*}$ \\
\hline ICU admission [N (\%)] & $3(5.36 \%)$ & $4(8.33 \%)$ & & $0.701^{*}$ \\
\hline 1-min APGAR score, mean \pm SD & $8.77 \pm 1.25$ & $8.58 \pm 1.7$ & 0.64 & 0.526 \\
\hline 5-min APGAR score, mean \pm SD & $9.57 \pm 0.81$ & $9.35 \pm 1.55$ & 0.92 & 0.362 \\
\hline
\end{tabular}

Note: *Fisher's exact test was used for comparisons ICU Intensive care unit, SD Standard deviation. 
Table 3 Comparison of the patients without an invasive placenta

\begin{tabular}{|c|c|c|c|c|}
\hline & No balloon occlusion group & Balloon occlusion group & $t(X 2)$ & $P$ \\
\hline N & 31 & 20 & & \\
\hline Intraoperative bleeding volume, $\mathrm{ml}$ (mean \pm SD) & $887.10 \pm 311.71$ & $690.00 \pm 226.88$ & 2.438 & 0.018 \\
\hline Hysterectomy [N (\%)] & $1(3.23 \%)$ & $0(0.00 \%)$ & & $0.658^{*}$ \\
\hline
\end{tabular}

Note: "Fisher's exact test was used for comparisons

$S D$ Standard deviation.

conducive to completely blocking uterine blood flow. The more invasive the placenta, the more obvious the changes in the blood vessels of the placenta [37]. Therefore, internal iliac artery balloon occlusion may not completely block the uterine blood supply of an invasive placenta.

In the study group, high-risk factors for hysterectomy were invasive placenta penetration, placenta invasive area $>1 / 2$ and abnormal vascular filling. The intra- and postsurgical outcomes of women affected by PAS are directly related to the depth and topography of placental invasion, and those affected by placenta percreta are at a higher risk of morbidity [38, 39]. Placenta percreta can invade through the myometrium and serosa, causing disastrous blood loss. Maternal mortality is as high as $10 \%$ [40]. The expected treatment failure rate for placenta percreta patients is $44 \%(8 / 18)$ [41]. The placental invasive area is large, the blood vessels on the uterine surface are characterised by hyperplasia, bleeding is increased, and the rate of hysterectomy is increased. The development of intrapelvic parasitic arteries in the gravid uterus is hypothesised as the main cause of bleeding [34]. In PAS, abnormal blood vessels can be found around the uterus and bladder. If the bladder and incision are not correctly identified, vascular damage and serious bleeding may occur. The lack of decidua in PAS leads to the highly invasive phenotype of extravillous trophoblasts as well as an imbalance and an increase in blood vessels at the site of invasion. The structure of blood vessels in the placental bed changes substantially, the distribution of blood vessels becomes uneven, and the size is uneven $[42,43]$. In this case, even if a balloon is used, efforts to preserve the uterus for the patient may fail. The patients in the study group who underwent hysterectomy at our hospital exhibited abnormal blood vessel filling, and all these patients had placenta percreta. Five of these cases had concomitant bladder invasion, and the amount of bleeding was not reduced after intervention. Four cases had urinary system injury during the operation. Adjusting the treatment plan during the operation in a timely and effective manner in such patients remains an important topic of discussion. Abdominal aortic balloon occlusion has reportedly been used in patients with abnormalities of placental invasion and placenta accreta $[44,45]$.

Although the internal artery balloon occlusion procedure to reduce bleeding during caesarean delivery shows some effectiveness, its side effects on patients should be considered. Balloon occlusion of the internal iliac artery requires bilateral femoral artery puncture and the use of two balloons, which increases the exposure time and trauma to patients during the operation and requires a fixed body position after the operation. The complications after vascular embolisation also remain controversial and may include ischaemic necrosis of the lower limbs, thrombosis of the internal iliac artery, haematoma at the puncture site, ischaemia-reperfusion injury of tissues and organs and acute renal failure, among others. Iliac artery thrombosis has been reported to be the most common complication, with a risk of approximately 5\% [44, 46, 47], which may be due to changes in maternal blood flow, vascular injury during puncture and the hypercoagulable state of blood during pregnancy [46]. One patient developed lower limb thrombosis on the first day after balloon occlusion of the internal iliac artery in our hospital after internal iliac artery embolisation. The patient underwent left femoral artery incision and embolisation + femoral artery artificial vessel bypass. The size of the balloon, the size of the arterial sheath and the time of balloon occlusion are important factors. If the balloon is too large, arterial injury may occur. If the balloon occlusion time is too long, thrombosis and reperfusion injury of the lower limbs may occur.

In addition, the foetal radiation exposure dose must be minimised. At the same exposure time [48], the X-ray dose of digital subtraction angiography (DSA) far exceeds the dose of fluoroscopy. Although this technology

Table 4 Comparison of the patients with an invasive placenta

\begin{tabular}{|c|c|c|c|c|}
\hline & No balloon occlusion group & Balloon occlusion group & $t(X 2)$ & P \\
\hline N & 25 & 28 & & \\
\hline Intraoperative bleeding volume, $\mathrm{ml}$ (mean \pm SD) & $1692.00 \pm 1280.60$ & $2085.71 \pm 1148.50$ & -1.18 & 0.243 \\
\hline Hysterectomy [N (\%)] & $6(24.00 \%)$ & $14(50.00 \%)$ & 3.8 & 0.051 \\
\hline
\end{tabular}

SD Standard deviation. 


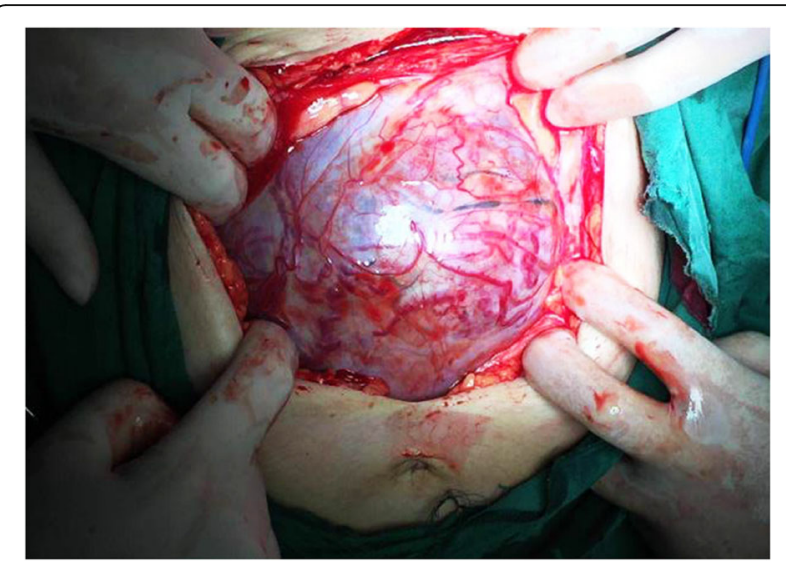

Fig. 1 At gestational week $36^{+2}$, total placenta previa with increased vascularity of the uterine serosa-bladder wall interface, myometrial thinning of the anterior wall and penetration of the placenta close to the serous layer is observed

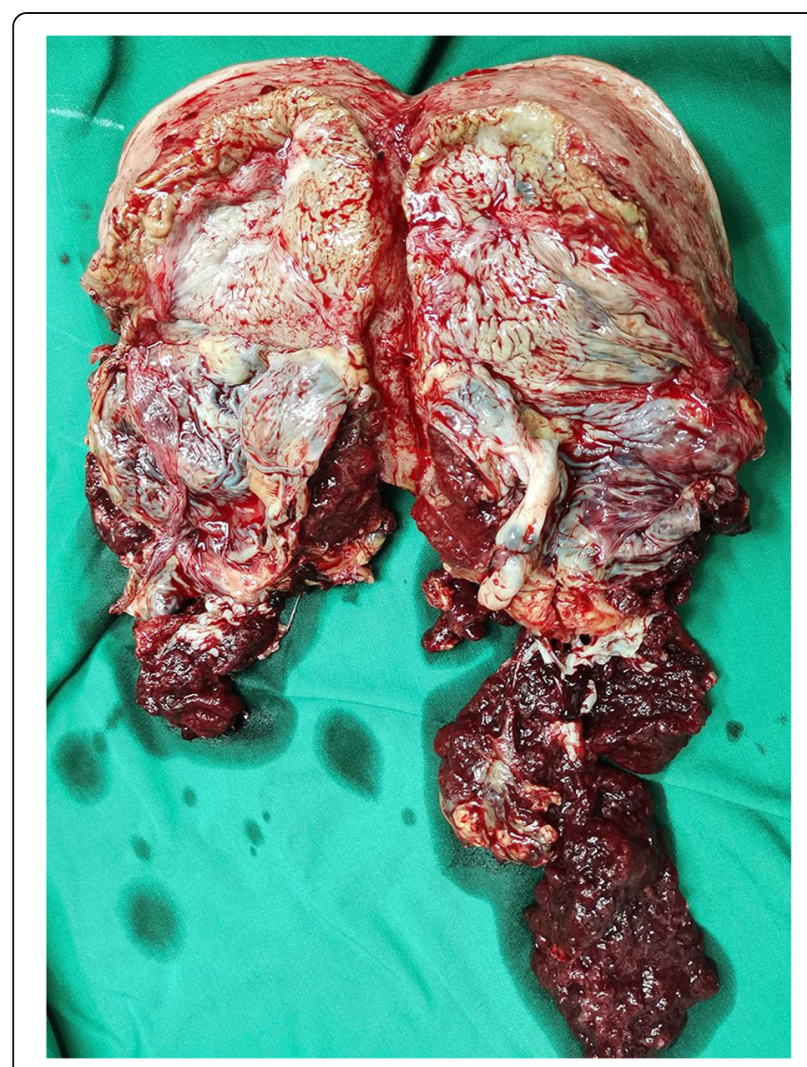

Fig. 2 At gestational week $35^{+2}$, total placenta previa with placentapenetrating invasion and a large invasive area is observed. No boundary between the uterus and placenta. Most of the placenta is located in the posterior wall of the uterus, where the myometrium is very thin

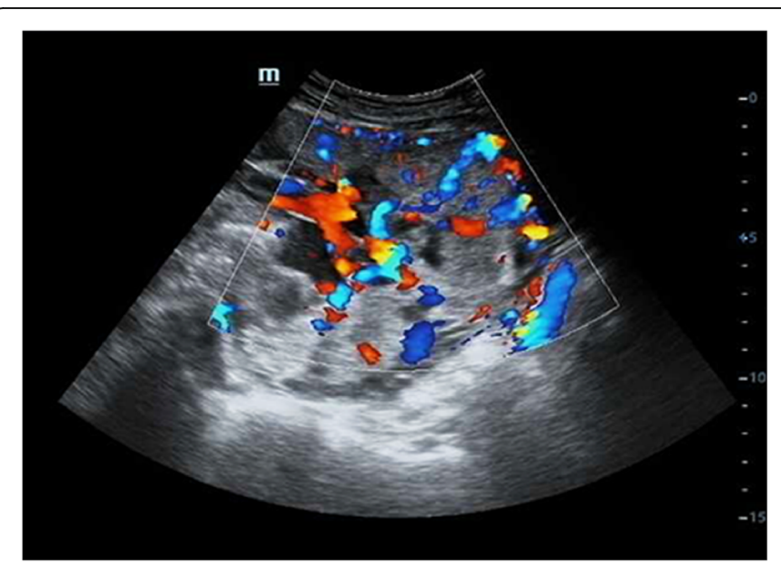

Fig. 3 Ultrasound (US) imaging at gestational week 37 reveals total placenta previa with multiple vascular lacunae within the placenta. The placenta in the anterior wall reaches the serous layer of the uterus, and thinning of the uterine serosa-bladder wall interface is observed. Power doppler showing increased vascularity

has been applied clinically for approximately 20 years, no consensus or data are available regarding the safe dose for the foetus, and further research and statistics are needed. Sun et al. [49] recommended a dose of $4.2 \pm 1.9$ mGy. To minimise radiation exposure, experienced interventional doctors should quickly insert the balloon into the internal iliac artery. During the follow-up of new-borns in our hospital, no complications caused by radiation were noted.

This study had certain limitations due to its retrospective and single-centre nature, its small sample size

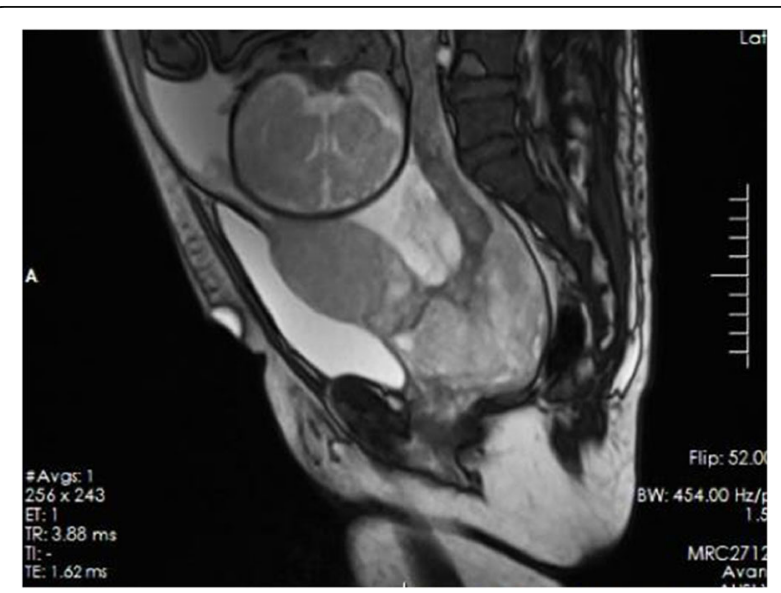

Fig. 4 Magnetic resonance imaging (MRI) at gestational week $36^{+5}$ reveals total placenta previa. The placenta is located mainly on the anterior side. A T2 dark band, uterine bulging, myometrial thinning of the anterior wall and myometrium loss between the placenta and bladder wall are observed. Multiple linear processes that had invaded into the myometrium are observed 
Table 5 Patients with and without hysterectomy in the study group

\begin{tabular}{|c|c|c|c|c|}
\hline Indicators & Unresected uterus & Hysterectomy & $t\left(X^{2}\right)$ & $P$ \\
\hline N & 34 & 14 & & \\
\hline Invasive placenta penetration [N (\%)] & $4(11.8 \%)$ & $12(85.7 \%)$ & 24.40 & 0.000 \\
\hline Placenta invasive area > 1/2 [N (\%)] & $9(26.5 \%)$ & $13(92.9 \%)$ & 17.60 & 0.000 \\
\hline Abnormal vascular filling [N (\%)] & $8(23.5 \%)$ & $12(85.7 \%)$ & 15.78 & 0.000 \\
\hline Previous caesarean section (mean \pm SD) & $1.21 \pm 0.48$ & $1.14 \pm 0.36$ & 0.44 & 0.661 \\
\hline
\end{tabular}

SD Standard deviation.

and possible selection bias. Thus, larger multi-centre studies are required.

\section{Conclusions}

In conclusion, the preventive use of an internal iliac artery balloon is one method for the treatment of PAS patients as this method can control bleeding during caesarean section. However, the need to control complications related to balloon occlusion warrants consideration. Indications should be strictly controlled. The benefits of reducing blood loss must be balanced with the invasiveness of this procedure and the risk of maternal adverse events [50], and doctor-patient communication should be comprehensive.

\section{Abbreviations}

PAS: Placenta accreta spectrum; MRI: Magnetic resonance imaging;

DSA: Digital subtraction angiography

\section{Acknowledgements}

The researchers thank the obstetrics and gynecology department, surgery department, and imaging department of Anhui Provincial Hospital for their support during the data collection process.

\section{Authors' contributions}

YP designed the entire study, wrote the proposal, participated in the data collection, analysed the data, and drafted the paper. $L$, CP, and DW approved the proposal with some revisions, participated in the data analysis, and revised the subsequent drafts of the paper. LC provided administrative, technical, and material support and provided a critical review of the intellectual content of the article. All authors read and approved the final manuscript.

\section{Funding}

No sources of funding exist for this research. All costs were covered by the researchers.

\section{Availability of data and materials}

The data sets used and analysed during the current study are available from the corresponding author upon reasonable request.

\section{Ethics approval and consent to participate}

Ethical permission was obtained by the ethical review committee of First Affiliated Hospital of University of Science and Technology of China (Anhui Provincial Hospital). Written informed consent was obtained from each participant. All identifying information of the participants was confidential.

\section{Consent for publication}

Not applicable.

\section{Competing interests}

The authors declare that they have no competing interests.
Received: 16 January 2020 Accepted: 29 May 2020

Published online: 08 June 2020

\section{References}

1. Chattopadhyay SK, Kharif H, Sherbeeni MM. Placenta praevia and accreta after previous caesarean section. Eur J Obstet Gynecol Reprod Biol. 1993;52: 151-6.

2. Melendez J, Siriwardhana S, Yoong W. Peripartum hysterectomy in the UK: management and outcomes of the associated haemorrhage. BJOG. 2008; 115:799-800.

3. Sheiner E, Sarid L, Levy A, Seidman DS, Hallak M. Obstetric risk factors and outcome of pregnancies complicated with early postpartum hemorrhage: a population-based study. J Matern Fetal Neonatal Med. 2005:18:149-54.

4. Jauniaux E, Ayres-de-Campos D, Langhoff-Roos J, Fox KA, Collins S. FIGO classification for the clinical diagnosis of placenta accreta spectrum disorders. Int J Gynaecol Obstet. 2019;146:20-4.

5. Silver RM, Barbour KD. Placenta accreta spectrum: accreta, increta, and percreta. Obstet Gynecol Clin N Am. 2015;42:381-402.

6. Silver RM, Landon MB, Rouse DJ, Leveno KJ, Spong CY, Thom EA, et al. Maternal morbidity associated with multiple repeat cesarean deliveries. Obstet Gynecol. 2006;107:1226-32.

7. Heena AB, Kumari G. Retrospective study of placenta accreta, placenta increta and placenta percreta in Peripartum hysterectomy specimens. Indian J Pathol Microbiol. 2020:63:S87-90.

8. Mulla BM, Weatherford R, Redhunt AM, Modest AM, Hacker MR, Hecht JL, et al. Hemorrhagic morbidity in placenta accreta spectrum with and without placenta previa. Arch Gynecol Obstet. 2019;300:1601-6.

9. Cim N, Tolunay HE, Boza B, Arslan H, Ates C, Ilik I, et al. Use of ARFI elastography in the prediction of placental invasion anomaly via a new virtual touch quantification technique. J Obstet Gynaecol. 2018;38:911-5.

10. Doumouchtsis SK, Papageorghiou AT, Vernier C, Arulkumaran S. Management of postpartum hemorrhage by uterine balloon tamponade: prospective evaluation of effectiveness. Acta Obstet Gynecol Scand. 2008;87: 849-55

11. Tunçalp O, Souza JP, Gülmezoglu M. New WHO recommendations on prevention and treatment of postpartum hemorrhage. Int J Gynaecol Obstet. 2013;123:254-6.

12. Wei J, Dai Y, Wang Z, Gu N, Ju H, Xu Y, et al. Intrauterine double-balloon tamponade vs gauze packing in the management of placenta previa a multicentre randomized controlled trial. Medicine (Baltimore). 2020;99: e19221.

13. Pala S, Atilgan R, Başpınar M, Kavak E, Yavuzkır S, Akyol A, et al. Comparison of results of Bakri balloon tamponade and caesarean hysterectomy in management of placenta accreta and increta: a retrospective study. J Obstet Gynaecol. 2018;38:194-9.

14. Shazly AEM, Badee AYA, Ali MK. The use of multiple 8 compression suturing as a novel procedure to preserve fertility in patients with placenta accreta: case series. Aust N Z J Obstet Gynaecol. 2012;52:395-9.

15. Kaplanoğlu M, Kaplanoğlu DK, Koyuncu O. A different approach to placenta previa accreta: intrauterine gauze compress combined B-Lynch uterine compression suture. Clin Exp Obstet Gynecol. 2015;42:53-6.

16. Mohan B, Wander G, Bansal R, Mutti J, Tandon P, Juneja S, et al. Intraoperative uterine artery embolization with caesarean delivery in an adjoining operating theatre and catheter lab (OT/CL) complex vs. conventional management in patients with abnormally invasive placenta: a retrospective case control study. J Obstet Gynaecol. 2020;40:324-9.

17. Raba G. Small invasive technique of internal iliac artery ligation for postpartum haemorrhage. Ginekol Pol. 2020;91:29-31. 
18. Maneschi F, Perrone S, Di Lucia A, laniri P. Shock parameters and shock index during severe post-partum haemorrhage and implications for management: a clinical study. J Obstet Gynaecol. 2020;40:40-5.

19. Committee on Obstetric Practice. ACOG committee opinion. Placenta accreta. Number 266, January 2002. American College of Obstetricians and Gynecologists. Int J Gynaecol Obstet. 2002;77:77-8.

20. Dwyer BK, Belogolovkin V, Tran L, Rao A, Carroll I, Barth R, et al. Prenatal diagnosis of placenta accreta: sonography or magnetic resonance imaging? J Ultrasound Med. 2008;27:1275-81.

21. Cali G, Giambanco L, Puccio G, Forlani F. Morbidly adherent placenta: evaluation of ultrasound diagnostic criteria and differentiation of placenta accreta from percreta. Ultrasound Obstet Gynecol. 2013;41:406-12.

22. Comstock $\mathrm{CH}$. The antenatal diagnosis of placental attachment disorders. Curr Opin Obstet Gynecol. 2011;23:117-22

23. Shih JC, Jaraquemada JMP, Su YN, Shyu MK, Lin CH, Lin SY, et al. Role of three-dimensional power doppler in the antenatal diagnosis of placenta accreta: comparison with gray-scale and color doppler techniques. Ultrasound Obstet Gynecol. 2009;33:193-203.

24. Geleto A, Chojenta C, Taddele T, Loxton D. Magnitude and determinants of obstetric case fatality rate among women with the direct causes of maternal deaths in Ethiopia: a national cross sectional study. BMC Pregnancy Childbirth. 2020;20:130.

25. Mehrabadi A, Hutcheon JA, Lee L, Liston RM, Joseph KS. Trends in postpartum hemorrhage from 2000 to 2009: a population-based study. BMC Pregnancy Childbirth. 2012;12:108.

26. Gulino FA, Guardo FD, Zambrotta E, Di Gregorio LM, Miranda A, Capriglione $\mathrm{S}$, et al. Placenta accreta and balloon catheterization: the experience of a single center and an update of latest evidence of literature. Arch Gynecol Obstet. 2018;298:83-8.

27. Carnevale FC, Kondo MM. de Oliveira Sousa W, Jr., Santos AB, da Motta Lea Filho JM, Moreira AM, et al. perioperative temporary occlusion of the internal iliac arteries as prophylaxis in cesarean section at risk of hemorrhage in placenta accreta. Cardiovasc Intervent Radiol. 2011;34:758-64.

28. Bodner L, Nosher JL, Gribbin C, Siegel RL, Beale S, Scorza W. Balloonassisted occlusion of the internal iliac arteries in patients with placenta accreta/percreta. Cardiovasc Intervent Radiol. 2006;29:354-61.

29. Chodraui-Filho SF, Monsignore LM, Freitas RK, Nakiri GS, de Carvalho CR, Duarte $\mathrm{G}$, et al. Can the combination of internal iliac temporary occlusion and uterine artery embolization reduce bleeding and the need for intraoperative blood transfusion in cases of invasive placentation? Clinics (Sao Paulo). 2019;74:e946.

30. Pinto PV, Machado AP, Montenegro N. Precesarean prophylactic balloon catheters for suspected placenta accreta: a randomized controlled trial. Obstet Gynecol. 2016;127:602

31. Shrivastava V, Nageotte M, Major C, Haydon M, Wing D. Case-control comparison of cesarean hysterectomy with and without prophylactic placement of intravascular balloon catheters for placenta accreta. Am J Obstet Gynecol. 2007;197:402.e1-5.

32. Salim R, Chulski A, Romano S, Garmi G, Rudin M, Shalev E. Precesarean prophylactic balloon catheters for suspected placenta accreta: a randomized controlled trial. Obstet Gynecol. 2015;126:1022-8.

33. Li K, Zou Y, Sun J, Wen H. Prophylactic balloon occlusion of internal iliac arteries, common iliac arteries and infrarenal abdominal aorta in pregnancies complicated by placenta accreta: a retrospective cohort study. Eur Radiol. 2018;28:4959-67.

34. Palacios Jaraquemada JM, García Mónaco R, Barbosa NE, Ferle L, Iriarte H, Conesa HA. Lower uterine blood supply: extrauterine anastomotic system and its application in surgical devascularization techniques. Acta Obstet Gynecol Scand. 2007;86:228-34.

35. Jha P, Pōder L, Bourgioti C, Bharwani N, Lewis S, Kamath A, et al. Society of abdominal radiology (SAR) and European society of urogenital radiology (ESUR) joint consensus statement for MR imaging of placenta accreta spectrum disorders. Eur Radiol. 2020. https://doi.org/10.1007/s00330-01906617-7.

36. Matsubara S, Kuwata T, Usui R, Watanabe T, Izumi A, Ohkuchi A, et al. Important surgical measures and techniques at cesarean hysterectomy for placenta previa accreta. Acta Obstet Gynecol Scand. 2013;92:372-7.

37. Jauniaux E, Collins SL, Jurkovic D, Burton GJ. Accreta placentation: a systematic review of prenatal ultrasound imaging and grading of villous invasiveness. Am J Obstet Gynecol. 2016:215:712-21.

38. Belfort MA. Placenta accreta. Am J Obstet Gynecol. 2010;203:430-9.
39. Jauniaux E, Ayres-de-Campos D. FIGO consensus guidelines on placenta accreta spectrum disorders: introduction. Int J Gynaecol Obstet. 2018;140: 261-4.

40. Price FV, Resnik E, Heller KA, Christopherson WA. Placenta previa percreta involving the urinary bladder: a report of two cases and review of the literature. Obstet Gynecol. 1991;78:508-11.

41. Sentilhes L, Ambroselli C, Kayem G, Provansal M, Fernandez H, Perrotin F, et al. Maternal outcome after conservative treatment of placenta accreta. Obstet Gynecol. 2010;115:526-34.

42. Duzyj CM, Buhimschi IA, Laky CA, Cozzini G, Zhao G, Wehrum M, et al. Extravillous trophoblast invasion in placenta accreta is associated with differential local expression of angiogenic and growth factors: a crosssectional study. BJOG. 2018;125:1441-8

43. Derman AY, Nikac V, Haberman S, Zelenko N, Opsha O, Flyer M. MRI of placenta accreta: a new imaging perspective. AJR Am J Roentgenol. 2011; 197:1514-21.

44. Greenberg Jl, Suliman A, Iranpour P, Angle N. Prophylactic balloon occlusion of the internal iliac arteries to treat abnormal placentation: a cautionary case. Am J Obstet Gynecol. 2007;197:470.e1-4.

45. Duan X, Chen P, Han X, Wang Y, Chen Z, Zhang X, et al. Intermittent aortic balloon occlusion combined with cesarean section for the treatment of patients with placenta previa complicated by placenta accreta: a retrospective study. J Obstet Gynaecol Res. 2018;44:1752-60.

46. Dilauro MD, Dason S, Athreya S. Prophylactic balloon occlusion of internal iliac arteries in women with placenta accreta: literature review and analysis. Clin Radiol. 2012;67:515-20.

47. Peng ZH, Xiong Z, Zhao BS, Zhang GB, Song W, Tao LX, et al. Prophylactic abdominal aortic balloon occlusion: an effective method of controlling hemorrhage in patients with placenta previa or accreta. Exp Ther Med. 2019;17:1492-6.

48. Harrington DP, Boxt LM, Murray PD. Digital subtraction angiography: overview of technical principles. AJR Am J Roentgenol. 1982;139:781-6.

49. Sun W, Duan S, Xin G, Xiao J, Hong F, Hong H, et al. Safety and efficacy of preoperative abdominal aortic balloon occlusion in placenta increta and/or percreta. J Surg Res. 2018;222:75-84.

50. Bishop S, Butler K, Monaghan S, Chan K, Murphy G, Edozien L. Multiple complications following the use of prophylactic internal iliac artery balloon catheterisation in a patient with placenta percreta. Int J Obstet Anesth. 2011;20:70-3.

\section{Publisher's Note}

Springer Nature remains neutral with regard to jurisdictional claims in published maps and institutional affiliations.

Ready to submit your research? Choose BMC and benefit from:

- fast, convenient online submission

- thorough peer review by experienced researchers in your field

- rapid publication on acceptance

- support for research data, including large and complex data types

- gold Open Access which fosters wider collaboration and increased citations

- maximum visibility for your research: over $100 \mathrm{M}$ website views per year

At BMC, research is always in progress.

Learn more biomedcentral.com/submissions 